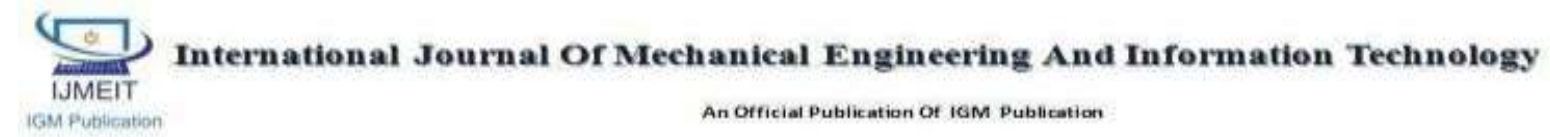

Index Copernicus Value-63.45

\title{
Modal Analysis of Francis Turbine Blade Using Composite Material
}

\author{
Authors \\ Shrenik B Gat ${ }^{1}$, Aditya Sawant ${ }^{2}$ \\ ${ }^{1,2}$ KJ College of Engineering \& Mgmt. Research Pune, India \\ Email-gat.shrenik@gmail.com, sawant.adi2008@gmail.com
}

\begin{abstract}
Performance of rotating equipment majorly depends upon mass of rotating components \& vibration occurring in them while in operation. Major rotating mass is in runner which tends to generate more vibration in the system. Thereby reducing weight of runner will not only reduce the vibration but also increase the overall efficiency. To reduce the weight we should concentrate on alternative material such as composites. Peak amplitude and damping behaviour is proven better in composite materials rather than in steels. In this paper we have conducted modal analysis through Ansys \& further the natural frequency results for Francis Turbine blade of stainless steel \& glass fibre are compared.

Keywords-Francis, Modal Analysis, Frequency, Glass Fibre, Composite
\end{abstract}

\section{INTRODUCTION}

The basic idea is to study the vibration response \& weight optimization that can be achieved using glass fibre as alternative material to stainless steel. Low density of Glass Fibre can significantly reduce the weight of turbine blade. Modal analysis performed on Francis Turbine blade made of stainless steel. First six mode shapes \& corresponding natural frequencies are determined. For the blade of same dimensions the material is changed to glass fibre and same procedure was repeated to get first six mode shapes and natural frequencies. It has been found that the vibration response of glass fibre blade is better compare to blade made of stainless steel. Also considerable weight reduction is achieved due to low density of glass fibre.

\section{LITERATURE REVIEW}

Standards/Manuals/Guidelines For Small Hydro Development, "Electro-Mechanical Works Guidelines for selection of Turbine and Governing System for SHP" has enlightened on types, classification and performance of various turbines.
Teodor Miloş, Mircea Bărglăzan, “Cad Technique Used To Optimize The Francis Runner Design”, this paper illustrates the technique that has been used to build the blade in CATIA.

Gizem Okyay, "Utilization Of CFD Tools In The Design Process Of A Francis Turbine” has various formulae as well as examples of turbine design.

Jitendra Kumar Sahu, Brijesh Patel, "Vibration Analysis of Turbine Blades -Using ANSYS", has discussed vibration analysis of turbine blades with various alloy steels, aluminium etc.

\section{CALCULATION OF BASIC DIMENSIONS}

To build the 3D model in CATIA we need to obtain few basic dimensions as shown in the fig 1 . To start with following input parameters of Devighat power station have been considered.

Power $\mathrm{P}_{\mathrm{d}}=4.8 \mathrm{MW}=4800 \mathrm{~kW}$

Specific Speed, $n_{q}=278 \mathrm{MHP}$

Design Head, $\mathrm{H}_{\mathrm{d}}=40 \mathrm{~m}$

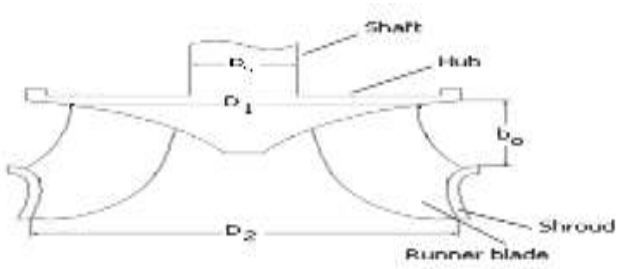

Fig.1 Various Dimensions of Francis Turbine 
Rotational Speed of Runner (n):

$$
\begin{aligned}
\mathrm{n} & =\mathrm{n}_{\mathrm{q}}\left(\mathrm{H}_{\mathrm{d}}{ }^{1.25} / \mathrm{P}_{\mathrm{d}}^{0.5}\right) \ldots \ldots \ldots \ldots \ldots \ldots . . \text { Eqn. } 1 \\
& =403.6 \mathrm{rpm}
\end{aligned}
$$

\section{Angular Rotational Speed of Runner ( $\omega)$ :}
$\omega=2 \pi \mathrm{n} / 60$
Eqn.2
$\omega=42.26 \mathrm{rad} / \mathrm{sec}$

Discharge $\left(Q_{d}\right)$ can be found using following relation

$P_{d}=\rho g Q_{d} H_{d} \eta$ Eqn.3

$$
\begin{aligned}
& 4800 \times 1000=1000 \times 9.81 \times Q_{d} \times 40 \times 0.91 \\
& \eta=0.91 \ldots \ldots \ldots \ldots \ldots \ldots \ldots \text {. } \ldots \text { assumed } \\
& \mathrm{Q}_{\mathrm{d}}=13.44 \mathrm{~m}^{3} / \mathrm{s}
\end{aligned}
$$

Shaft Diameter $\left(\mathrm{D}_{\text {shaft }}\right)$ :

$\mathrm{D}_{\text {shaft }}=105\left(\mathrm{P}_{\mathrm{d}} / \mathrm{n}\right)^{0.35}$ Eqn. 4

$D_{\text {shaft }}=249.77 \mathrm{~mm}=250 \mathrm{~mm}$

\section{Determination of the Exit Diameter $\left(\mathrm{D}_{2}\right)$ :}

Meridional flow velocity $\left(\mathrm{V}_{2 \mathrm{~m}}\right)$ at the runner exit

$\mathrm{V}_{2 \mathrm{~m}}=\operatorname{SQRT}\left(2 \mathrm{gH}_{\mathrm{d}} \varepsilon\right)$ .Eqn.5

where the variable $\varepsilon$ is calculated by the following equation

$\varepsilon^{2}=1.16 \times 10^{-3}\left[\left(\delta_{\mathrm{r}} \eta_{\mathrm{q}} / \mathrm{SQRT} \mathrm{k}\right) \tan \beta\right]^{4 / 3}$. Eqn.6

$\left(\delta_{\mathrm{r}}=1, \mathrm{k}=1, \beta=24.5^{0}\right)$ assumed

$\varepsilon=0.8591$

$\mathrm{V}_{2 \mathrm{~m}}=25.966 \mathrm{~m} / \mathrm{s}$

The exit diameter $\left(\mathrm{D}_{2}\right)$ :

$\mathrm{D}_{2}=\operatorname{SQRT}\left[4 \mathrm{Q}_{\mathrm{d}} / \pi \mathrm{V}_{2 \mathrm{~m}}\right]$ Eqn.7

$\mathrm{D}_{2}=0.8118 \mathrm{~m}=811.8 \mathrm{~mm}=812 \mathrm{~mm}$

\section{Determination of the Inlet Diameter $\left(D_{1}\right)$}

$\mathrm{V}_{1 \mathrm{~m}}=\mathrm{V}_{2 \mathrm{~m}}=25.966 \mathrm{~m} / \mathrm{s}$ assumed

The inlet circumferential velocity $\left(\mathrm{u}_{1}\right)$, $\mathrm{u}_{1}=\mathrm{V}_{1 \mathrm{~m}} / 2 \tan \beta_{1}+\operatorname{SQRT}\left[\left(\mathrm{V}_{1 \mathrm{~m}} / 2 \tan \beta_{1}\right)^{2}+\mathrm{gH}_{\mathrm{d}} \eta\right] \ldots \ldots$.Eqn. 8 $\left(\beta_{1}=83^{0}\right)$ assumed

$\mathrm{u}_{1}=20.6 \mathrm{~m} / \mathrm{s}$

The inlet diameter,

$$
\begin{aligned}
\mathrm{D}_{1} & =2 \mathrm{u}_{1} / \omega \ldots \ldots \ldots \ldots \ldots \ldots \ldots \ldots \ldots \ldots \ldots \ldots \ldots \ldots \ldots \\
& =0.9749 \mathrm{~m}=974.9 \mathrm{~mm}=975 \mathrm{~mm}
\end{aligned}
$$

Determination of the Wicket Gate Height $\left(b_{0}\right)$ :

$$
\begin{aligned}
& \mathrm{A}_{1}=\left(\pi \mathrm{D}_{1}\right) \mathrm{b}_{0} \ldots \ldots \ldots \ldots \ldots \ldots \ldots . . . \ldots q n .10 \\
& \mathrm{Q}_{\mathrm{d}}=\mathrm{A}_{1} \mathrm{~V}_{1 \mathrm{~m}} \ldots \ldots \ldots \ldots \ldots \ldots \ldots \text {. } \ldots q n .11 \\
& \text { Hence, } \\
& \qquad \mathrm{b}_{0=} \mathrm{Q}_{\mathrm{d}} /\left(\pi \mathrm{D}_{1} \mathrm{~V}_{1 \mathrm{~m}}\right) \\
& \quad \mathrm{b}_{0}=0.169116 \mathrm{~m}=169.116 \mathrm{~mm}=170 \mathrm{~mm}
\end{aligned}
$$

\subsection{Thickness of Turbine Blade}

Fig 2 shows the relationship between $\%$ camber length and the thickness in terms of $\%$ of camber length. From CATIA model we have measured camber length which is $191.145 \mathrm{~mm}$. The maximum thickness of the aerofoil is at the $40 \%$ of camber length measured from the leading edge. Hence from above graph the thickness for $40 \%$ of camber length is given as follows:

Thickness $=6 \%$ of the camber length

$$
=0.06 \times 191.145=11.47 \mathrm{~mm} \sim 12 \mathrm{~mm} \text {. } .
$$

Since we are not dealing with any CFD elements, the blade of single uniform thickness is modelled in CATIA.

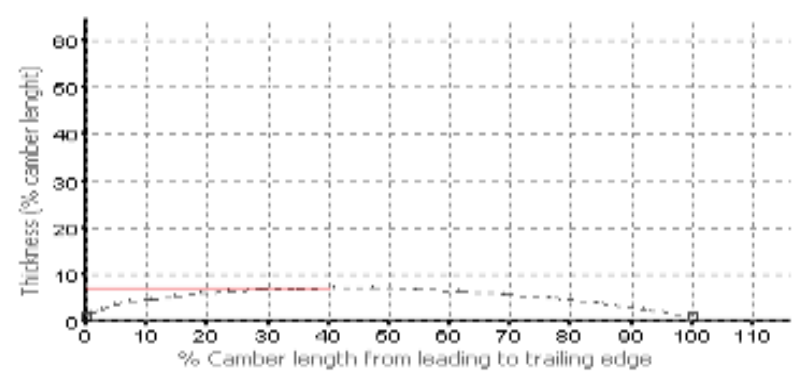

Fig.2 Thickness v/s Camber Length

\section{GENERATION OF CAD MODEL}

Dimensions required for modelling are calulcated in the earlier steps. The calculated dimensions are fitted to match fig 6 meridional views. Further CAD model of a blade have been prepared in CATIA. Fig 4, $5 \& 6$ are important to build 3D model in CATIA whereas fig 3 shows isometric view of turbine along with shaft and blade.

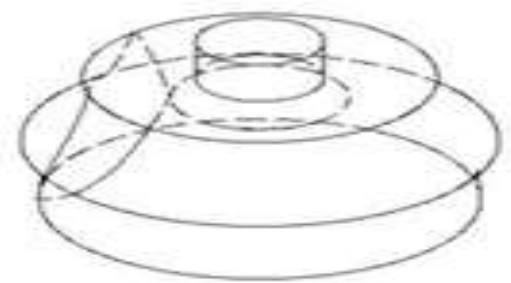

Fig.3 Isometric View 


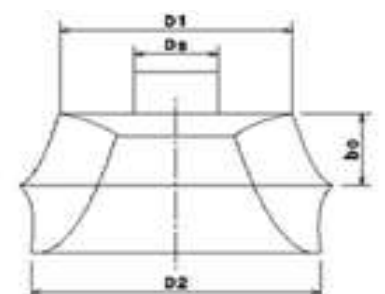

Fig.4 Meridional Plane View

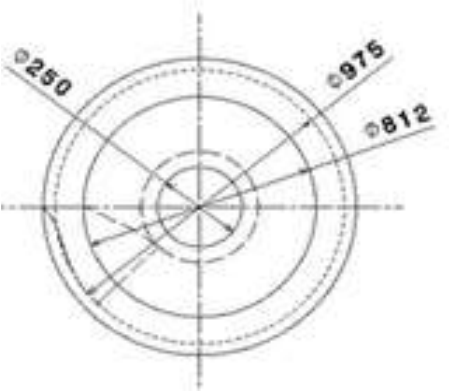

Fig.5 Plan View

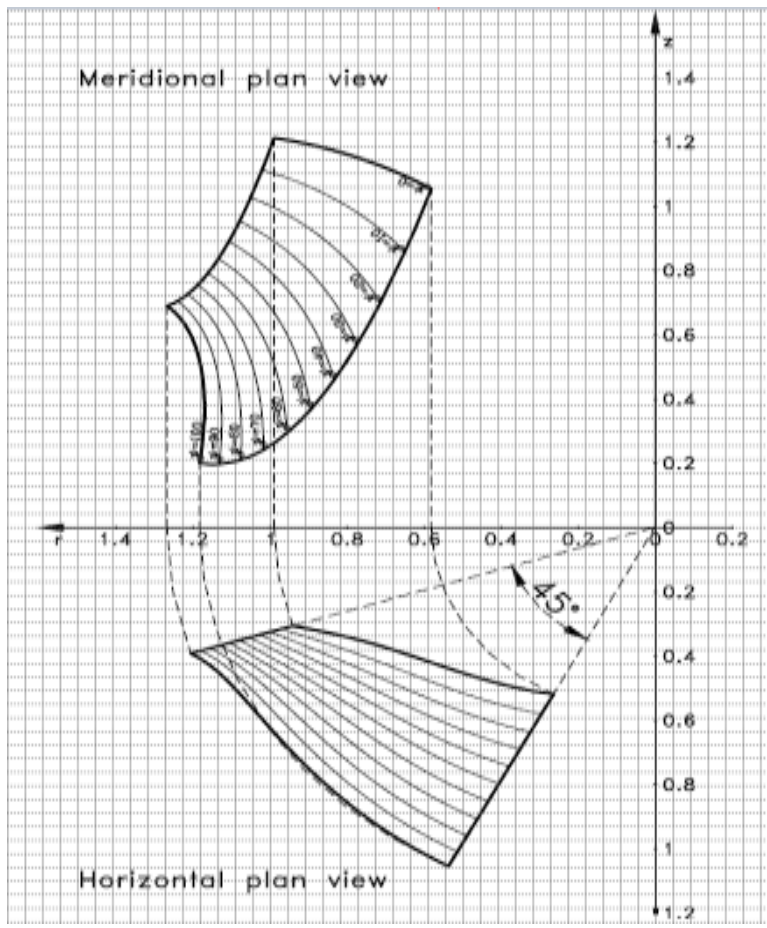

Fig. 6 Meridional Views

Following are various views of blade modelled in CATIA

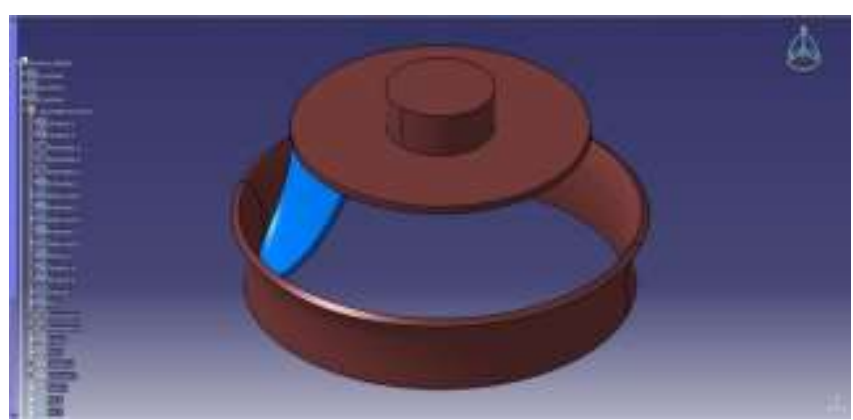

Fig. 7 CATIA Model of Blade of Francis Turbine with Hub, Shroud and Shaft

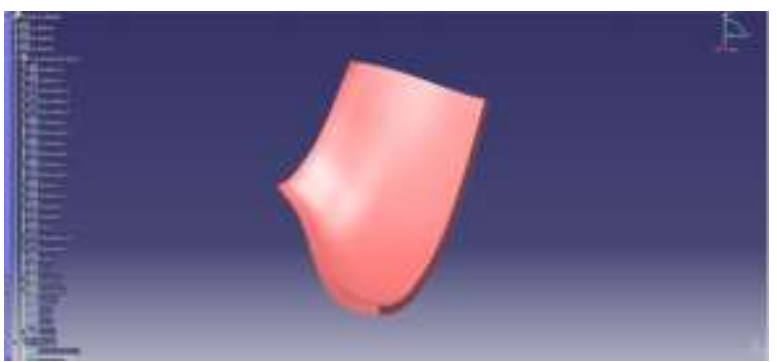

Fig. 8 Front View of Blade in CATIA

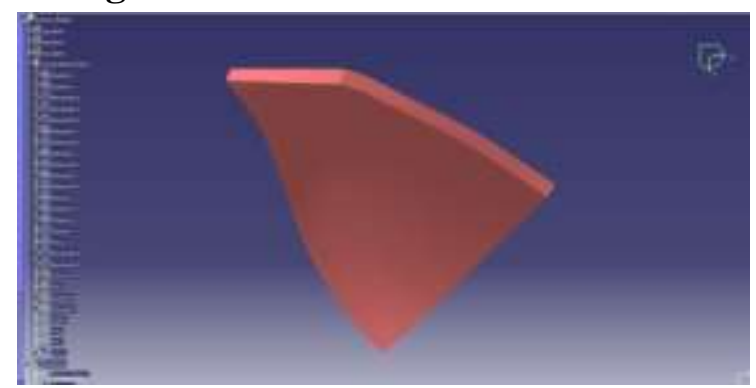

Fig. 9 Top View of Blade in CATIA

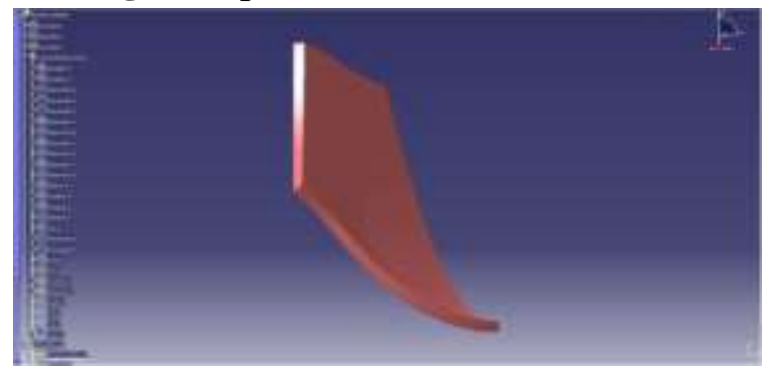

Fig. 10 Side View of Blade in CATIA

\section{FINITE ELEMENT MODELLING AND MODAL ANALYSIS OF BLADE}

Initially the .igs file from CATIA is imported to the meshing software Hypermesh. The CAD data of the blade is imported and the surfaces were created and meshed with Solid 45 (3D Mesh Element Type). Fig 11 shows meshed blade model. The model is imported in ANSYS to perform modal analysis and various mode shapes and their respective natural frequencies are obtained. Initially modal analysis is performed on blade with stainless steel material \& later it is performed on blade of glass fibre.

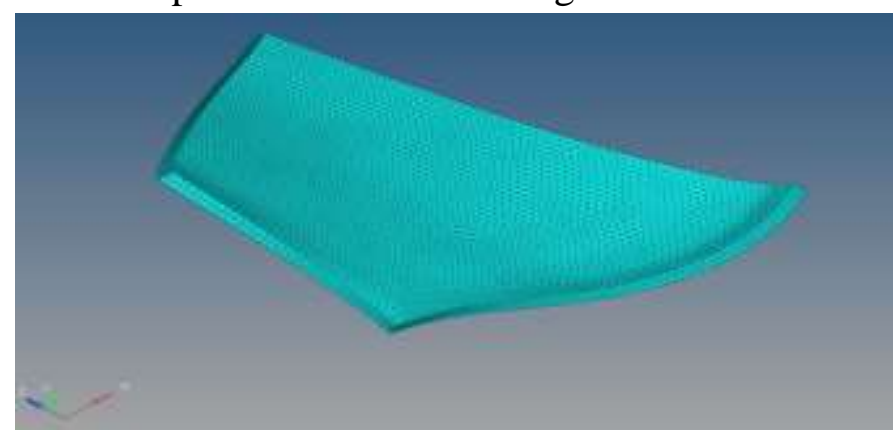

Fig. 11 Meshed Blade (Element Type- Solid 45) 


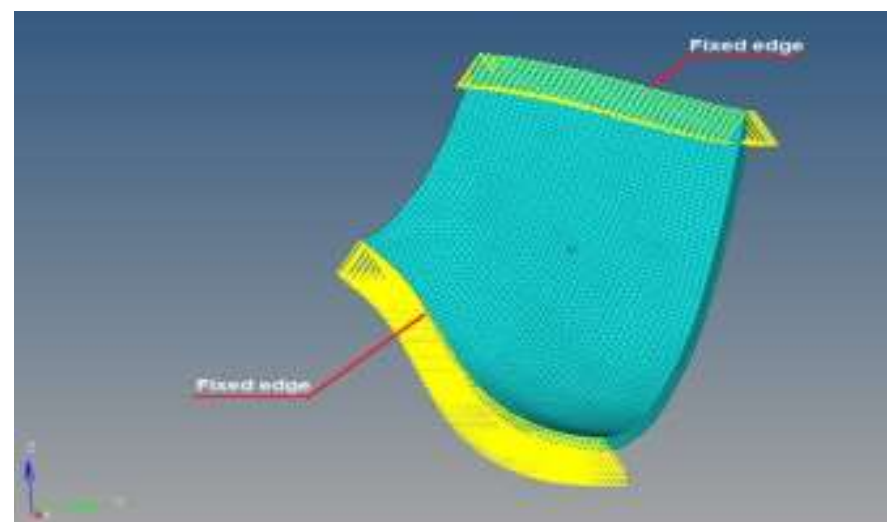

Fig. 12 Meshed Blade with Boundary Conditions

Table 1 Properties of Stainless Steel

\begin{tabular}{|c|c|}
\hline Property & Value \\
\hline Young's Modulus & $200 \mathrm{Gpa}$ \\
\hline Poisson's Ratio & 0.29 \\
\hline Density & $8000 \mathrm{~kg} / \mathrm{m} 3$ \\
\hline Yield Stress & $215 \mathrm{Mpa}$ \\
\hline Ultimate Tensile Strength & $505 \mathrm{Mpa}$ \\
\hline
\end{tabular}

Table 2 Properties of Glass Fibre

\begin{tabular}{|c|c|}
\hline Property & Value \\
\hline Young's Modulus in X Dir. & $40300 \mathrm{Mpa}$ \\
\hline Young's Modulus in Y Dir. & $6210 \mathrm{Mpa}$ \\
\hline Young's Modulus in Z Dir. & $40300 \mathrm{Mpa}$ \\
\hline Poisson Ratio & 0.2 \\
\hline Density & $1.9 \times 10^{-9}$ tonne/mm3 \\
\hline Shear Modulus in XY Plane & $3070 \mathrm{Mpa}$ \\
\hline Shear Modulus in YZ Plane & $2390 \mathrm{Mpa}$ \\
\hline Shear Modulus in XZ Plane & $1550 \mathrm{Mpa}$ \\
\hline
\end{tabular}

\section{a) Mode Shapes \& Natural Frequencies of}

\section{Stainless Steel Blade}

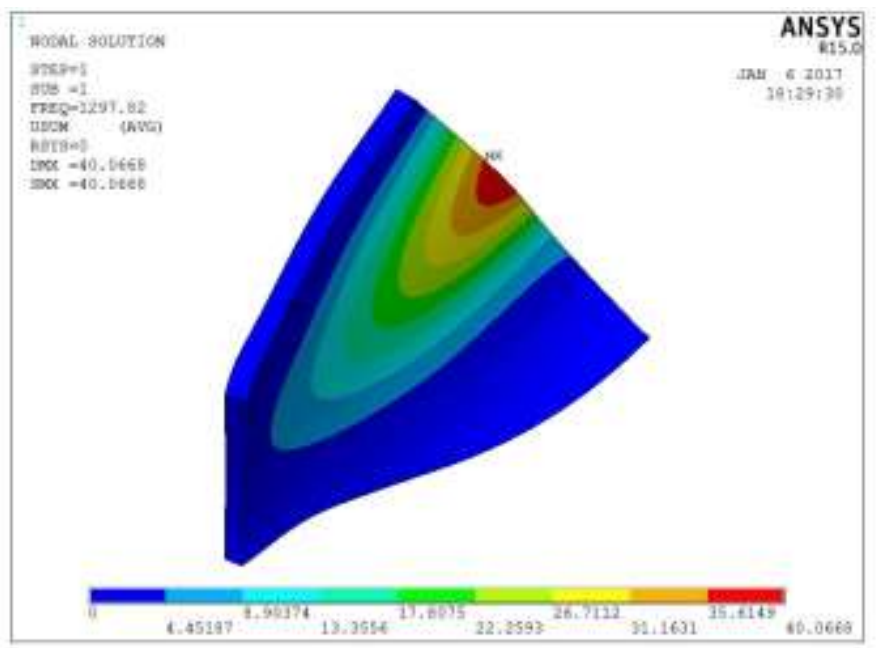

Fig. 13 Mode shape 1 with frequency $1297.82 \mathrm{~Hz}$

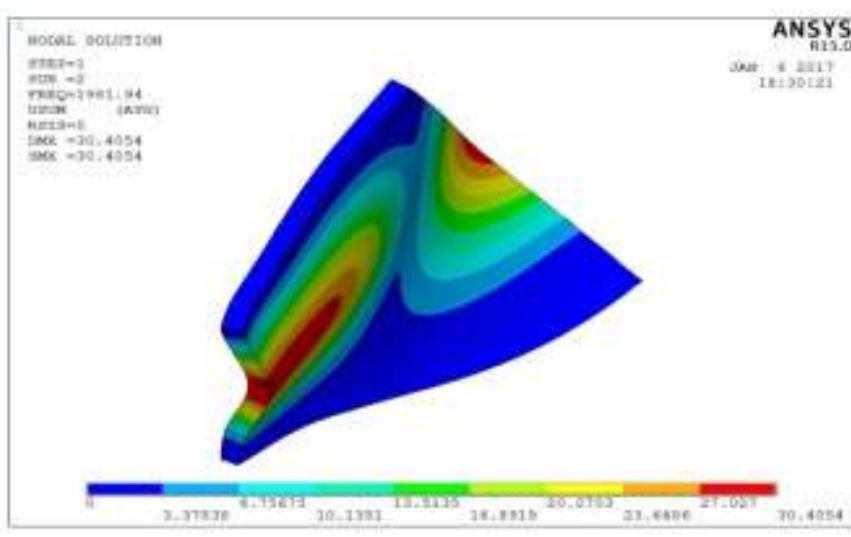

Fig. 14 Mode shape 2 with frequency $1981.94 \mathrm{~Hz}$

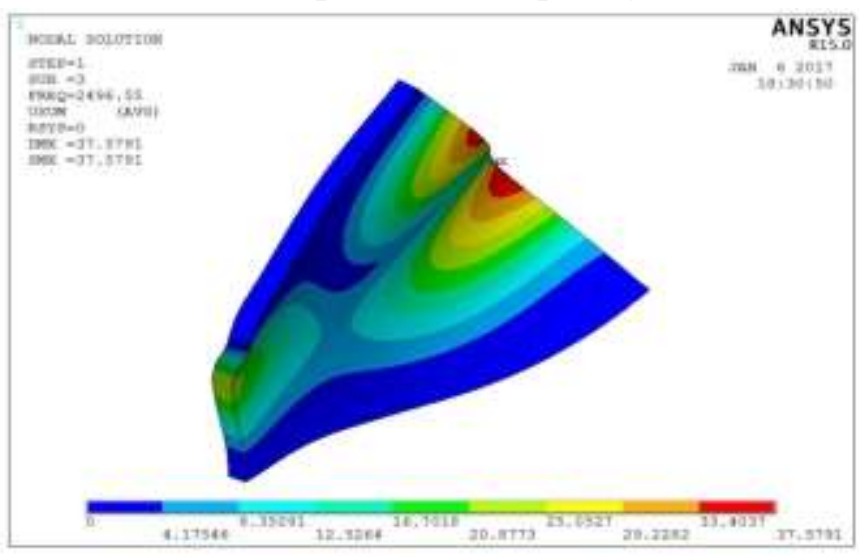

Fig. 15 Mode shape 3 deflection with frequency $2496.55 \mathrm{~Hz}$

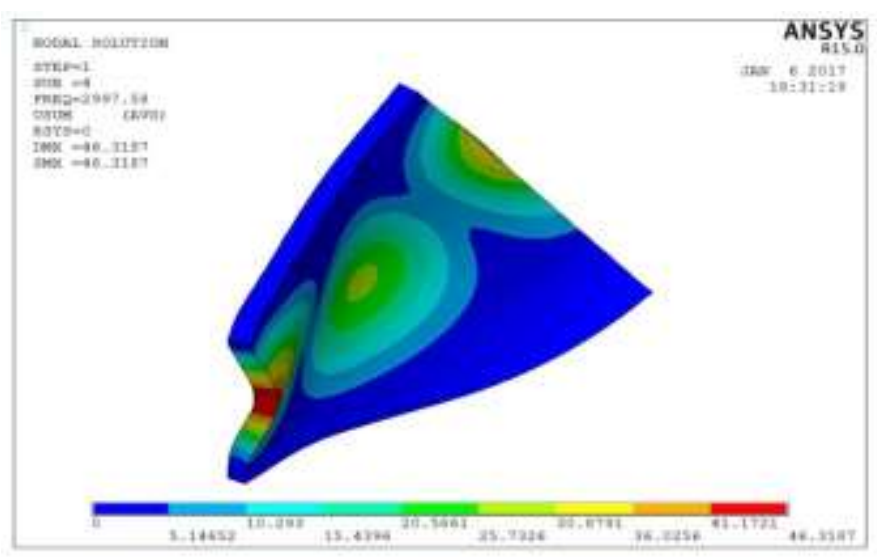

Fig. 16 Mode shape 4 deflection with frequency $2997.58 \mathrm{~Hz}$

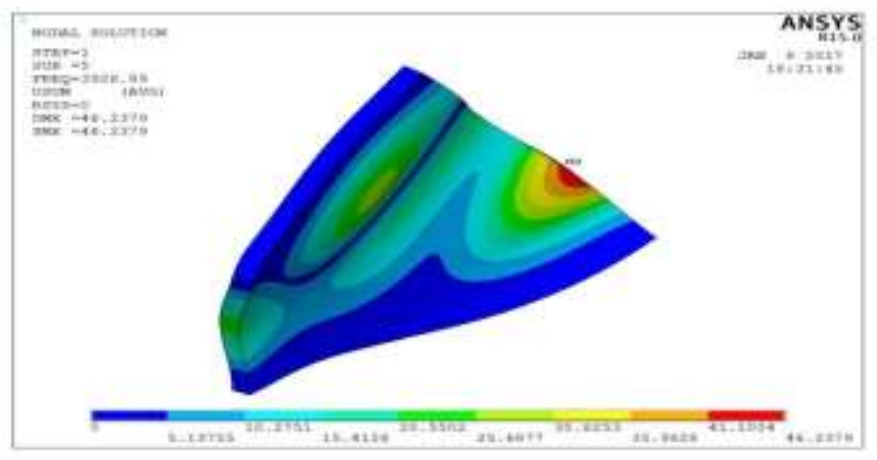

Fig. 17 Mode shape 5 with frequency $3926.89 \mathrm{~Hz}$ 


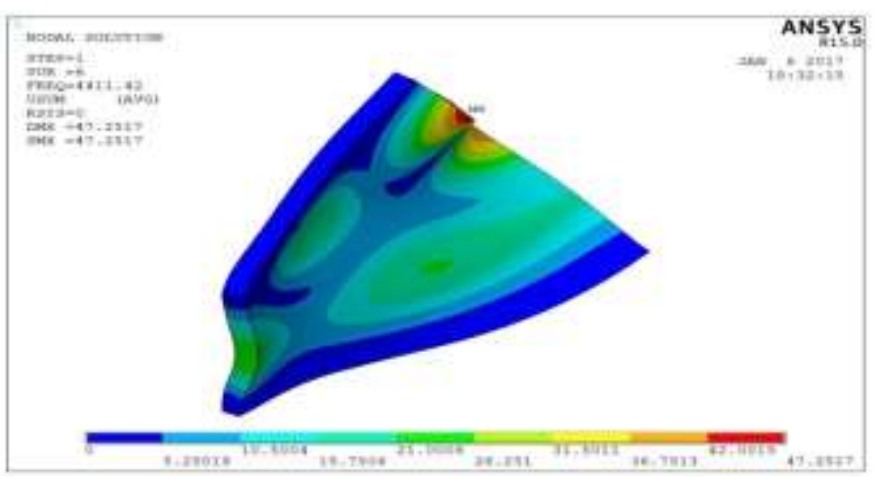

Fig. 18 Mode shape 6 with frequency $4411.42 \mathrm{~Hz}$

\section{b) Mode Shapes \& Natural Frequencies of Glass} Fibre Blade

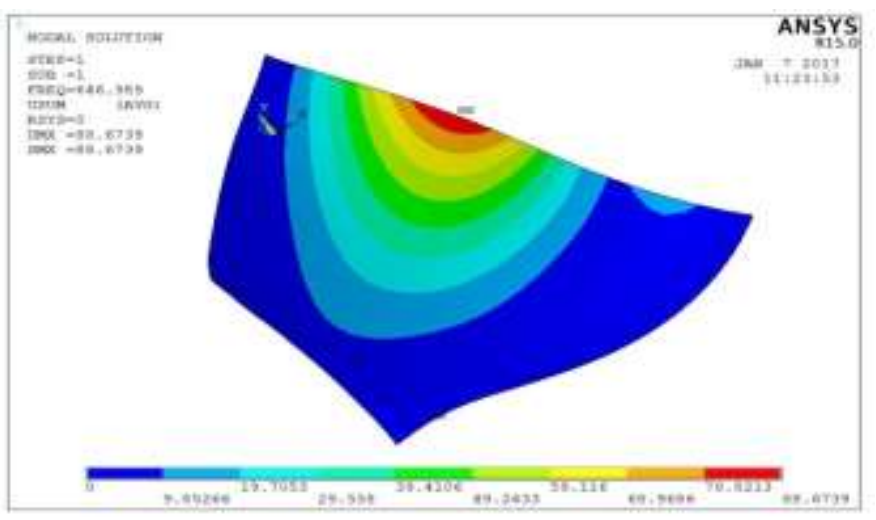

Fig. 19 Mode shape 1 with frequency $646.989 \mathrm{~Hz}$

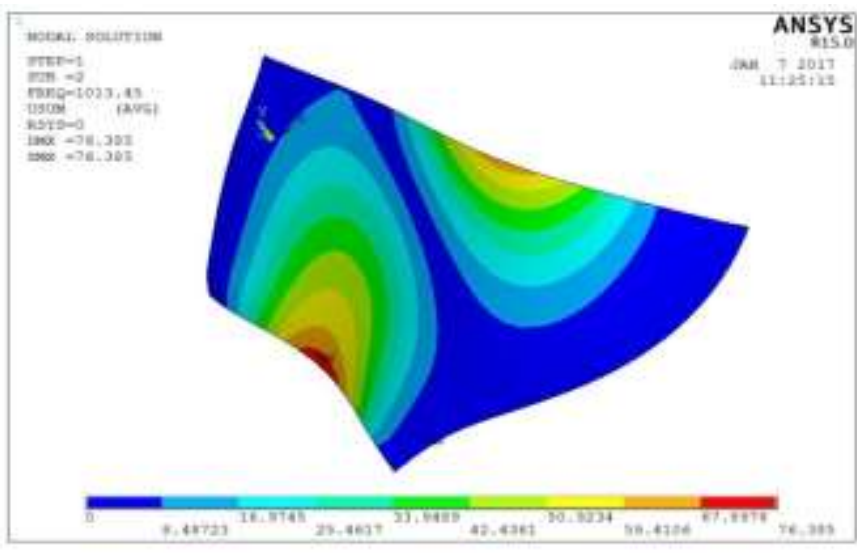

Fig. 20 Mode shape 2 with frequency $1013.45 \mathrm{~Hz}$

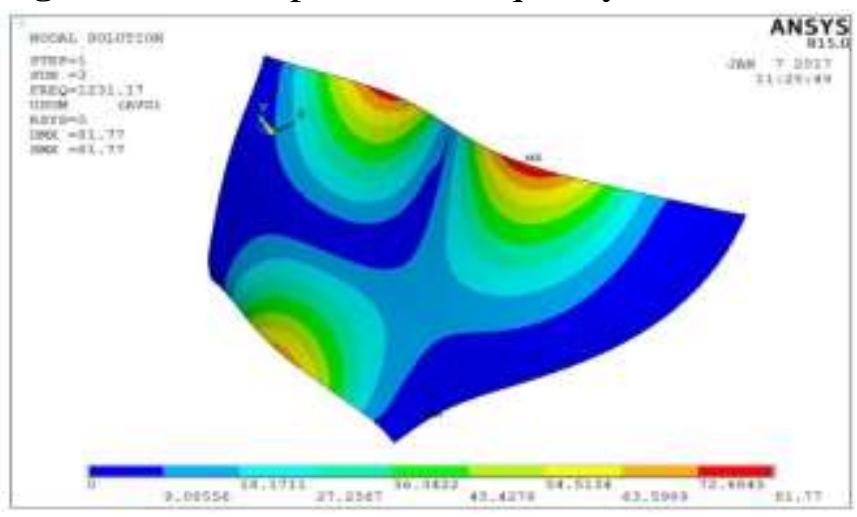

Fig. 21 Mode shape 3 with frequency $1231.17 \mathrm{~Hz}$

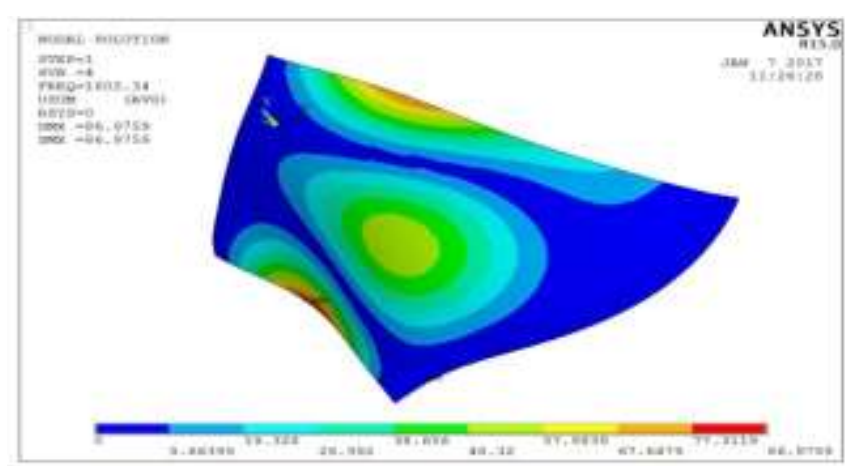

Fig. 22 Mode shape 4 frequency $1602.34 \mathrm{~Hz}$

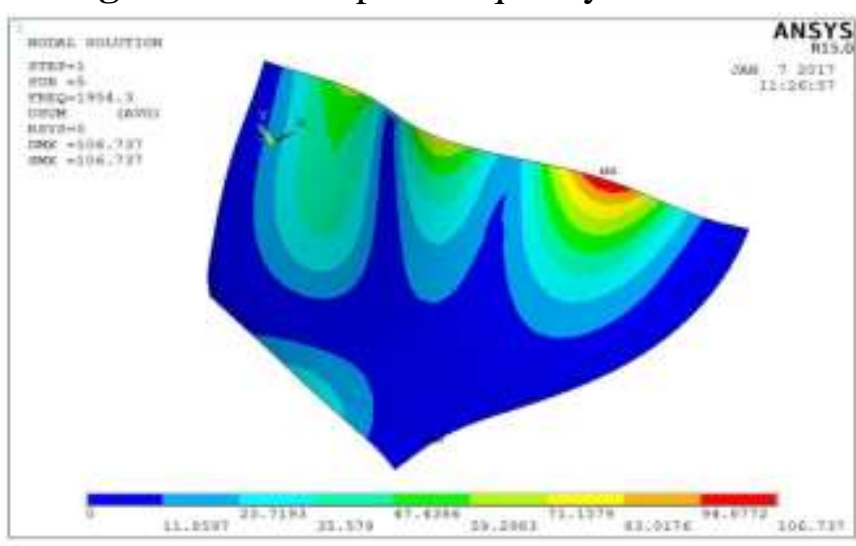

Fig. 23 Mode shape 5 with frequency $1954.30 \mathrm{~Hz}$

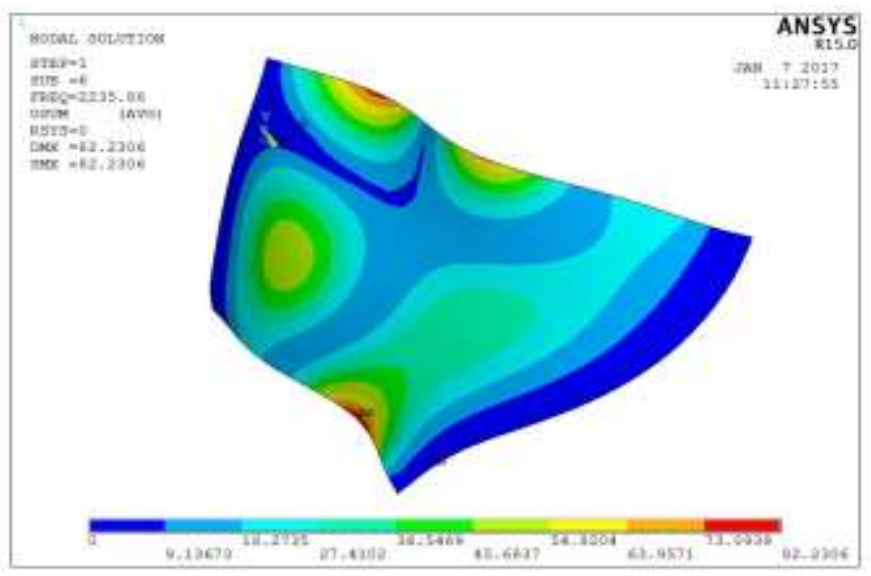

Fig. 24 Mode shape 6 with frequency $2235.86 \mathrm{~Hz}$

Table 3 Comparison of Natural Frequencies

\begin{tabular}{|c|c|c|c|}
\hline \multirow{2}{*}{ Sr. No } & \multirow{2}{*}{ Mode } & \multicolumn{2}{|c|}{ Frequency in Hz } \\
\cline { 3 - 4 } & & Stainless Steel & Glass Fibre \\
\hline 1 & 1 & 1297.82 & 646.989 \\
\hline 2 & 2 & 1981.94 & 1013.45 \\
\hline 3 & 3 & 2496.55 & 1231.17 \\
\hline 4 & 4 & 2997.58 & 1602.34 \\
\hline 5 & 5 & 3926.89 & 1954.30 \\
\hline 6 & 6 & 4411.42 & 2235.86 \\
\hline
\end{tabular}

\section{CONCLUSIONS}

- The comparison, between modal analysis results of turbine blade with Stainless Steel 
and Glass Fiber as materials, has been performed and it is summarized in table shown above.

- Frequencies of vibration of the composite turbine blade in six different modes are lower than that of Stainless Steel turbine blade.

- Glass Fibre is proven to be better in damping behaviour.

- From CATIA model it is seen that approximately $75 \%$ weight of the blade can be reduced using Glass Fibre of same dimensions as of Stainless Steel.

- Further the frequencies obtained for Glass Fibre through modal analysis need to be verified experimentally.

- Detail study with respect CFD considerations \& accordingly fatigue analysis shall be considered as future research work.

\section{REFERENCES}

1. Standards/Manuals/Guidelines For Small Hydro Development, "Electro-Mechanical Works - Guidelines for selection of Turbine and Governing System for SHP”, Alternate Hydro Energy Center Indian Institute of Technology Roorkee, Ministry of New and Renewable Energy Govt. of India.

2. Gizem Okyay, "Utilization Of CFD Tools In The Design Process Of A Francis Turbine”, A Thesis Submitted To The Graduate School Of Natural And Applied Sciences Of Middle East Technical University, September 2010.

3. Teodor Miloş, Mircea Bărglăzan, "Cad Technique Used To Optimize The Francis Runner Design", Scientific Bulletin of the Politehnica University of Timisoara Transactions on Mechanics, The 6th International Conference on Hydraulic Machinery and Hydrodynamics Timisoara, Romania, October 21 - 22, 2004

4. Jitendra Kumar Sahu, Brijesh Patel, "Vibration Analysis of Turbine Blades Using ANSYS”, International Journal Of
Scientific Research And Education, Volume 3 , Issue 1, Pages-2739-2749, January-2015, ISSN (e): 2321-7545 